\title{
IN PURSUIT OF COMPATIBILITY IN URBAN CONTEXT An Analytical Study with Special References to Contemporary Local Contexts in Cairo
}

\author{
Yasmeen El Semary \\ Assistant Professor \\ Arab Academy for ST\&MT \\ Smart Village, Egypt
}

\author{
Basil Ahmed Kamel \\ Prof.of Arch.\& Urban Theory \\ The American Univ. in \\ CairoNew Cairo, Ejypt
}

\author{
Ahmed Mohamed Amin \\ Professor of Architecture \\ Cairo University \\ Giza, Egypt
}

\begin{abstract}
In the past decades, an increased dissatisfaction with the built environment had been grown, despite the fact that several countries have developed legislative requirements to control the aesthetics of the urban environment, yet there is a growing difference between the view of the public and the professionals. One can also argue that the lack of empirical visual urban studies contributes to this gap. This paper investigates the validity of the previous hypothesis. The aim is to verify local urban spaces and their compatibility levels to local cultural language. A survey is conducted in several districts exploring the architectural features from the perspective of the professionals on one hand and the laymen on the other. The compatibility ratings were analysed by factor analysis. The results outline factors affecting the contextual compatibility in Cairo, highlighting non-homogeneous urban fabrics, evaluating the different architectural features which replicate or contrast with the context. These outcomes may help overcome the problems we are facing nowadays where architects and urban designers dismiss public taste in the design of local urban environments.
\end{abstract}

Keywords:Contextual Compatibility; Site Organization; Visual Compatibility; Factor Component Analysis.

\section{INTRODUCTION}

Contextual compatibility has received intensive attention throughout the last few decades. In order to achieve this compatibility, several aspects should be considered to allow for a perfect fit. These could be numerated as physical, perceptual, cultural, environmental and also conceptual. As perceived, the most influential aspect is foremost the perceptual compatibility (Abu-Obeid, 2009;Groat, 1983). Although it would seem that any adequate analysis of building features relevant to contextual fit would be difficult to achieve, yet many theorists had tried to solve this problem by suggesting conceptual frameworks for specifying physical features that are relevant to contextual fit. As noted by Abu-Obeid in his article titled. "Cognitive-Mathematic Approaches for evaluating Architectural Contextual Fit, Harrison and Howard (1980) pointed out aspects such as shape, pattern, form, colour, size, material, and design as physical features that form strong images to users and observers (Abu-Obeid, 2009 ; Auburn, Barnes, 2006). Others such as Harvey and Henri Lefebvre concentrated more on phenomenological references bridging between semiotics and experiences of space with reference to cultural preferences (Lefebvre, 1996;Lefebvre, 2003; Lefebvre, 2009). Accordingly, the fit in the contextual representation has been interpreted traditionally either through physical design strategies or philosophical concepts, cues, signs and symbols.

Several studies and surveys have concluded that building facades are the main and primary indicator to judgement on buildings. Along the lines of Harrison and Howard, Bentley (1985) pointed out what he called "contextual cues" such as windows, doors and wall details as variables to the contextual fit. Stamps (1995), on the other hand, underlined a method through a study he conducted to validate principles of contextual urban design as means of control to contextual fit. He identified scale and character as two variables that would match old buildings to new (Brolin, 2002; Groat, 1988).

As indicated, the several outlined approaches seem to lack generality by focusing on some physical aspects or phenomenological indicators. The approach outlined by Linda Groat appears to be more general, discussing and investigating a wide range of design factors, not only the façade components as stated by other theorists (Groat, 1983). Based on several analytical studies she pointed out aspects that would allow for site organization and defining façade features mainly massing, style and space occupation that would lead to a fit between the old and the new. Moreover, she also confirmed that the most influential elements in judging compatibility are façade components (Groat, 1988).

There are scholars who investigated the contextual compatibility through physical attributes only such as Bentley and Stamps. Yet others with Groat, such as Kevin Lynch, Christopher Alexander and Gordon Cullen had investigated the compatibility from a different perspective (Lynch 1960;Alexander 1977;Jencks 1999; Cullen 1991\&Cullen 2012) dividing the contextual compatibility into three types (compatibility as a function of visual continuity, compatibility through deeper levels of meaning and association, compatibility as a reflection of history). It is this variety of ways that compatibility may actually be interpreted and is hypothesized to be the optimum for this investigation to be fulfilled (Groat 1988).

Accordingly in order to investigate contextual compatibility a survey will be conducted investigating 
its types and focusing on different design features which are the components of any design strategy. This will be conducted exploring several case studies in different places, asking about different physical attributes, patterns, and urban features. Guided questionnaires with frequent users and laymen as well as experts are conducted to verify this investigation.

\section{RESEARCH PROBLEM}

"Architecture always influences the perception, memory, and clarity of the images that people form about their environments. Within the context, environmental mystery can be better understood by the perception of contextual fit." Auburn and Barnes (2006)

Certainly the designer has a great challenge to find out and create well suited Architecture or contextually compatible Architecture. Although architects usually visualize and familiarize themselves with the context, both physically and conceptually, yet their designs transcend the observed surroundings and create their own context. Sometimes this can be due to extreme abstraction or intentionally to stand out. This is considered a commonly observed problem in several sites today. By result, local contexts and urban spaces lack compatibility, character, and their own style; consequently they lack the feeling of place as well as the identity.

In different setting types such as residential, commercial and also public, it is more and more common to identify lack of social identity, cultural spirit of place and fittingness between old and new buildings and settings and within the newly built environments as well. Many regions have conflict in some characteristics, such as: colour, height, material, and volume between buildings. One can see different façade colours and materials in the same street not matching with each other. Furthermore, conflict is obvious between the ground ribbon and the upper part of the building in commercial streets; shops under residential buildings have different colours, materials and proportions than the building above leading to nonhomogeneous facades. It is important to note that even though the paper will investigate all types of compatibility whether environmental, physical, cultural, conceptual, and/or perceptual, yet it will concentrate on the perceptual as being the easiest to the laymen to identify and the most influential to the experts.From several observations as indicated below in table (1), it is obvious that architects lack considering compatibility in context. The research main problem notes that although Architects are aware of the need for contextual compatibility, there is a need to develop a framework for analysing, assessing and evaluating contextual compatibility in different Cairene settings.

Based on the literature review, the research applies an empirical study to verify the extent of perception of the attributes for contextual compatibility between professionals and laymen. The compatibility ratings were analysed by factor analysis, specifically the Principal Component Analysis "PCA" method. The results outline factors affecting the contextual compatibility in Cairo, highlighting non-homogeneous urban fabrics, testing and evaluating the different architectural features and physical attributes which replicate or contrast with the context.The paper's main objective is to prove that façade components/features have the strongest effect on compatibility judgment due to laymen and experts and not only experts as stated by theorists, also to investigate the contexts within the compatibility as a function of visual continuity, compatibility through deeper levels of meaning and association, and compatibility as a reflection of history.

Table 1: several observations indicate the research problem (source: Authors).

\begin{tabular}{|l|l|l|l|}
\hline $\begin{array}{l}\text { Conflict in } \\
\text { the same } \\
\text { street } \\
\text { between } \\
\text { colors, } \\
\text { heights, } \\
\text { volumes, and } \\
\text { materials. }\end{array}$
\end{tabular}




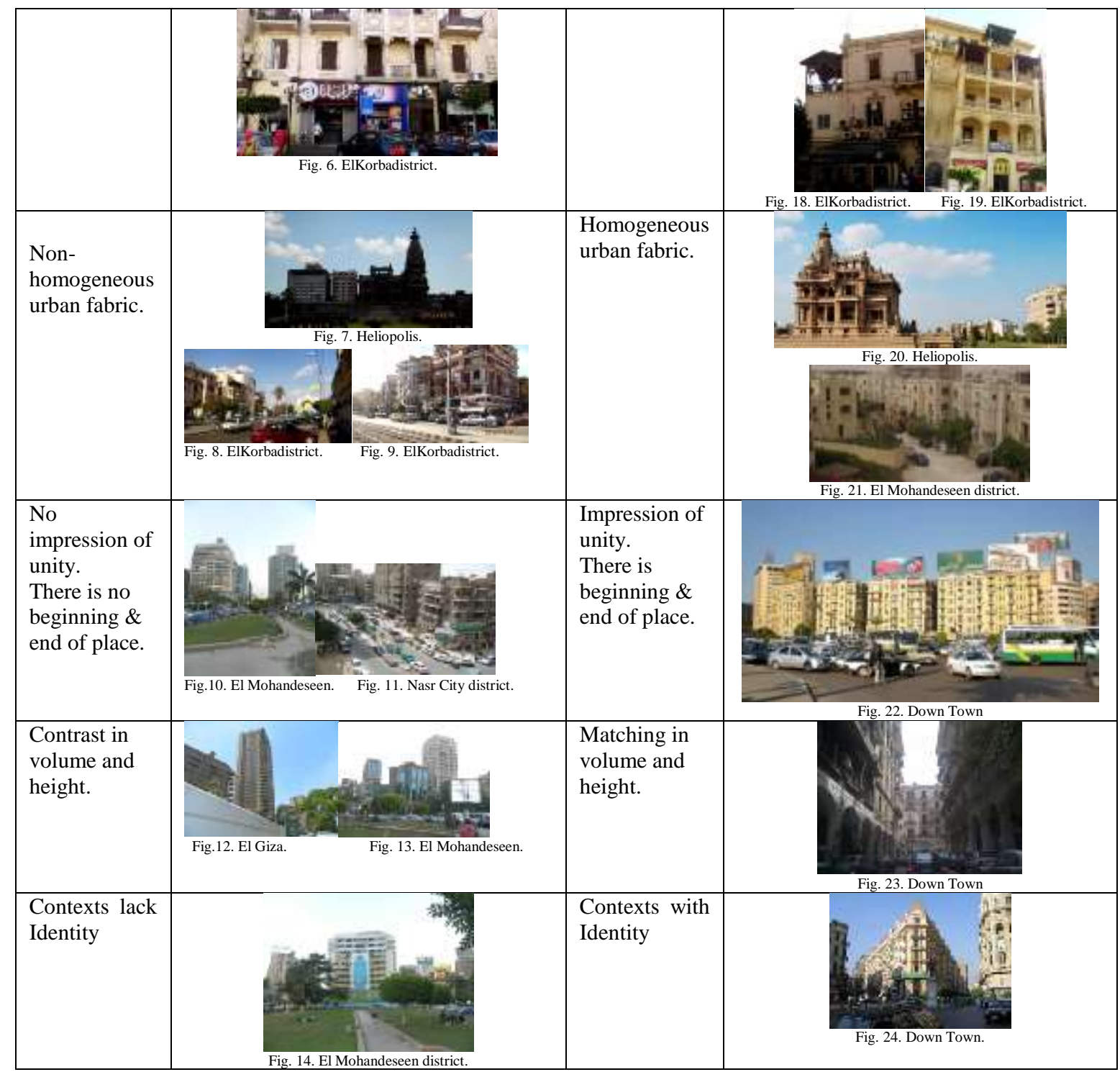

\section{TOWARDS CONTEXTUAL COMPATIBILITY IN URBAN SETTINGS}

Recently, the term "contextual architecture" is interpreted and understood by contemporary western architects of the last two decades, not just as being the architecture that necessarily deals with finding the appropriate physical attributes to be borrowed or copied from the surroundings, but also as being the architecture that captures, in different ways and on several levels of interpretation, the spirit of the surroundings (Groat, 1995). This evokes a variation in the criteria of evaluating architectural work as being contextually compatible. Capturing the spirit of the surroundings is much more appreciated than simply copying from the existing vocabulary; innovative architects' works are better evaluated when achieving compatibility through thisstrategy (Rice, 1980). Yet compatibility means consistency, appropriateness, suitability, convenience and fittingness as well, while fittingness is the criterion that has been suggested always against which the applicability of qualitative and quantitative studies should be evaluated (Groat, 1988;Rice, 1980;Milligan,1979). However in this research the term compatibility will be used in the practical investigation.

Moreover measuring the compatibility is completed by analysing activity patterns of users with respect to the designed physical environment, by identifying the functional properties of a specific setting (Lefebvre, 2009). So far the residential setting differs from the commercial and recreational setting, in their functional and physical properties. This paper is concentrating on the residential settings although shedding the light on other settings is also important in gaining contextual compatibility, but the study decided to leave the recreational and commercial settings to further studies. 


\section{FACTORS AFFECTING USER'S PERSPECTIVES}

Several studies have confirmed that there is a considerable difference between designers and lay people / users as to how they perceive, recognize and 'like' built environments. This is namely due to the difference in schemata used by both. Nevertheless it is the meanings as observed by the users and lay people is the one that most matters as it represents everyday life and environments (Bonta, 1979; Jencks, 1980). This illustrates how many architectural practitioners and critics frequently record how they expect people to interpret or react to specific physical attributes of an environment and how they evaluate compatibility or consistency (Rapoport, 1982).A common assumption is that people perceive things mostly in common if they are put under the same circumstances and in the same viewing position. However there are many factors that together influence the user and differ from one person to the other and none can be examined or can be fully understood out of context. So any event in context needs users, during the following part; factors affecting the users will be discovered and discussed (Auburn, 2006).

Factors affecting the user's perspectives are many; Background, beliefs and experience of the user, his work, traditions, preferences, observations and his behaviour in the contexts (Kjellström, 2011). In the following arguments, some of these factors will be discussed.

\subsection{User's Beliefs Impact on Compatibility} In his study, Jack L. Nasarexamined the individual differences in perception. The examination indicates that the differences probably result from variations in the socio-physical context, also he referred to what Evans (1982) had found about the impact of the socio physical context on users, for example the impact of symbolic significance was reduced in a city lacking symbolic buildings, the impact of singular function was reduced in a city lacking singular function buildings, moreover the impact of signs was reduced for a less cultured population. These all related to User's beliefs. Firthermore, the emphasis on significance and building access - which are important concerns to the laymen was higher in the examination for elder respondents than for others (Nasar, 1989).

From this examination, factors like cultural level and age of respondents had been occurred, if the respondent is less literate or less cultured, then his background and beliefs will be limited, his perspective will be influenced by these factors as well, they affect the user's beliefs. Hence, building 'recall' won't be enhanced by exposure and visual contrast only, but also his beliefs and backgrounds play an important role, and influence the personal reflection towards the context (Milligan, 1979).

\subsection{User's Preferences Impact on Compatibility}

In urban, the factor of preference at many times is related to way finding and orientation, or what do people rely on when first learning their way around an unfamiliar place, so perception of some physical elements rather than others may help in liking and preferring those elements than others in the context, for example some studies find paths as more important, others find landmarks as more important. Aside from the effects of variations in the task and scale of environment, the differences probably result from differences in physical context. However, and as a general observation, it is landmarks in cities are more important to new comers than paths (Nasar, 1989;Lynch, 1960).

On another stance, preference is related to the familiarity of the object to the laymen, some facades for example contain details that are more familiar to laymen than others. Moreover, preference provides a general evaluation measure defining the relation between an object and a group of people or class and is concerned with aesthetic evaluations (Altman, 1980;Lessig, 1998)

\subsection{User's Observation Impact on Compatibility}

One of the major theories related to perceiving the built environment is what Kevin Lynch introduced defining place legibility. How people understand and recognize place was manifested in his analogy through isolating a set of features of the built environment that would allow for its vibrancy and attractiveness. Developing a mental map of the city for Lynch was key to understand what the city contains of such references that associate with people's cognition (Lynch, 1960). These mental representations that are developed by the individual and recognized by the laymen are defined by Lynch as a network of paths, edges, districts, nodes, and landmarks.

To verify his theory, Lynch conducted a series of questionnaire surveys, and interviews in the central area of Boston, Jersey City and Los Angeles (Lynch, 1960; Banerjee, 1990).Building on the outcome of how people mapped places in these central city areas, he concluded that in order for a place to have a high mental image, its elements should be strongly defined and recognized by its inhabitants not only from physical point of view but also from a meaningful measure.

The more there is ambiguity and confusion in these elements, the less the spatial recognition. Hence, edges, districts, nodes, and landmarks are favourable contributors to imaging and when placed in good form, increase human ability to observe, see and remember patterns, and hence increase the contextual compatibility (Banerjee, 1990; Plata,2009).

\subsection{User's Behaviour Impact on Compatibility}

The patterns of interaction between people and the built environment are considered an important factor in environmental psychology studies. These ordinary behavioural patterns in ordinary settings are the focus of several studies to capture the notion of how the feel of a "place" emerges as an outcome of people relationships with the physical environment in which 
they act(Vahabzadeh, 2001; Davis, 1999). As a main function of this concept, the idea of the orderliness of people's interaction with the physical environment. Stokols and Shumaker (1981) in their account of 'People in places' argue that settings are "a particular place in which specific individuals share recurring patterns of activity and experience"(Davis, 1999).

However Jack Nasar identified the user's behaviour as the spatial behaviour which, refers to how people use the environment, which places they visit, which places they avoid, how long they stay. This spatial behaviour can be observed directly, measured indirectly through its traces, or estimated from verbal report of behavioural intent or how individuals expect to use an environment(Nasar, 1989). The behaviour impact on compatibility is usually accounted for as the least although it is a significant factor in forming the meaningful image of a place.

\section{ATTRIBUTES UNDER INVESTIGATION}

As this study aims at exploring the relationships between attributes of contextual compatibility in different regions, and based on the above stated literature review these attributes are summarized as follows: three major attributes, divided into minor attributes; (Site Arrangement: size, composite fittingness, height, Mass: shape, volume, scale, Façade Features: colour, texture, materials, style, openings, overall details). Depending on the loadings of these variables in the survey, compatibility can be investigated highlighting the difference between liking/preference and appropriateness. Preference will be measured by Laymen's perspective, while Appropriateness will be measured by Experts' perspective. The questionnaire held in each context can say which type of compatibility is perceived and why, aiming to find the three types of compatibility (compatibility as a function of visual continuity, compatibility through deeper levels of meaning and association, and compatibility as a reflection of history) in all contexts.

\section{EMPIRICAL ANALYSIS METHOD 6.1 Participants}

As far as this paper is concerned with compatibility in contemporary contexts, compatibility then should be discussed and understood in a practical way, thus a questionnaire is designed for laymen and experts, aiming to shed the light on possible gap/overlap between meanings of compatibility in the minds of intellectuals/laymen and designers.

The sample consisted of 100 volunteers, 50 laymen and 50 architects, the sample fulfilled a number of criteria including: unfamiliarity with the selected sites, fitting in a range of age groups, and belonging to various groups representing different social classes such as students, governmental employees, architects, academic staff, and small business employees.

6.2 Study Areas(see Fig. 1-24 in Table 1)

A wide panoramic view of Cairo is taken in the questionnaire to investigate the contextual compatibility in different sites, referring to different regions; Fatimid Cairo as an example of a historical context, ElKorba as an example of an old traditional and cultural context, New Cairo referring to a new residential compound, Nasr City as an example of a new developed context, and El Mohandeseen district as a crowded and high density context. It is worth to say that there are many contexts valid for these criteria but due to the study constraints, the research concentrates on these five contexts only.

\subsection{Stimuli}

The contexts in the questionnaire consisted of 5 printed coloured photographs " $14 \times 8 \mathrm{~cm}$ " of the 5 selected sites. Printed photographs were recommended by many researchers and were found valid representation techniques (Hennink, 2011).A strong relationship has been found between responses given to photographs and responses to places in situations, for that the photograph in this case is necessary to introduce the context to the volunteers as shown in the following figures $(25,26)$.

The 5 photographs were selected among 100 photographs taken from the 5 sites. The criteria for selections included:

- Variety between familiar contexts and unfamiliar contexts to the users and experts.

- Variety between styles (classic, baroque, neo baroque, modern).

- Variety between eras (old era and new era).

- Variety between residential contexts, either compounds or streets.

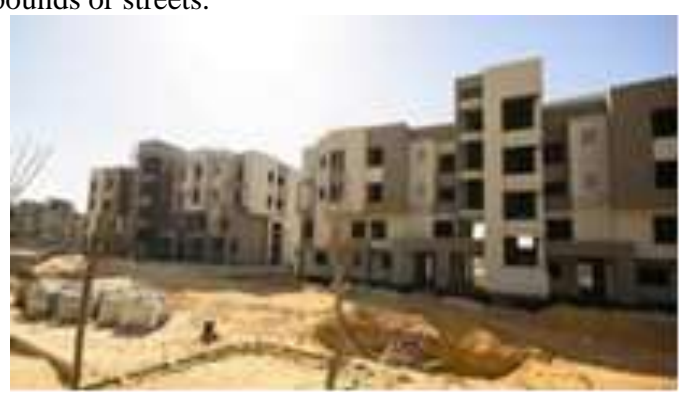

Fig.25. the photograph for New Cairo

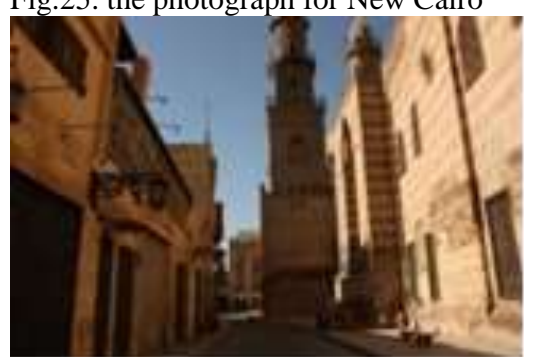

Fig.26 the photograph for Fatimid Cairo (source: Authors)

\subsection{Procedure}

A photo-questionnaire was distributed among the volunteers. The questionnaire form had five pages, every page stands for one context of the selected sites with a picture refers to the context, the first page is for the Fatimid Cairo, the second page is for Nasr City district, the third page shows ElKorba district, the fourth stands for New Cairo district, and the last one stands for El Mohandeseen district. It indicated that the 
volunteers whether architects or laymen would be evaluating 5 photographs.

The questionnaire is designed starting with a demographic data about the layman and the expert then a table containing the elements of the contextual design strategy including the three parts (site organization, mass, façade features) then the last part in the table asking about compatibility and its types, compatibility through visual continuity, compatibility through levels of meaning and compatibility as a reflection of history, whether any of them exists in the picture of the questionnaire from the volunteer point of view, asking the respondents to answer 15 questions representing the 15 variables about each photograph referring to each site. The variables included are required to be rated in a scale from 1 to 5 where 1 is referring to contrast and 5 is referring to replication. For example, "To what extent do you find the size compatible?" 5 points rating scale was used to answer each of the 15 questions. The scale ranged from 1 (not at all) to 5 (very much).

\subsection{Results}

As stated before in the research objective, the main aim of the study is exploring the relationships between the attributes of contextual compatibility (VISUAL COMPATABILITY: Site Arrangement: size, composite fittingness, height, Mass: shape, volume, scale, Façade Features: colour, texture, materials, style, openings, overall details. HISTORICAL COMPATABILITY \& MEANING COMPATABILITY (socio-cultural)), also evaluating these attributes and then determining the most effective and which type of compatibility is more perceived.

A statistical method was applied to test the relationship between compatibility and ratings of elements of architecture. The method applied Multivariate Factor Analysis using Component Loading and Commonality and Principle Component Analysis (PCA), just as seen below (sample, this was conducted to all areas, details of information for different locations and radar charts are not included in the paper).

Table (2) Laymen Component Matrix shows component loading of variables and commonality of variables, the highest component loading is openings; Loadings above 0.50 are in bold Component Matrix. The most common variable in Fatimid Cairo is visual compatibility. (Source: Authors)

\begin{tabular}{|c|c|c|c|c|c|c|c|}
\hline \multicolumn{2}{|c|}{ Variable } & $\begin{array}{l}\text { Factor } 1 \\
41.282 \%\end{array}$ & $\begin{array}{l}\text { Factor } 2 \\
17.252 \%\end{array}$ & $\begin{array}{l}\text { Factor } 3 \\
9.690 \%\end{array}$ & $\begin{array}{l}\text { Factor } 4 \\
7.488 \%\end{array}$ & Commonality & \multirow{2}{*}{ Radar Chart for Commonality } \\
\hline \multirow{3}{*}{ 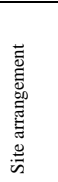 } & size & .543 & .419 & .504 & -.245 & 0.783 & \\
\hline & $\begin{array}{l}\text { composite } \\
\text { fittingness }\end{array}$ & .695 & -.395 & -.066 & .201 & 0.68 & \multirow{4}{*}{ menne- } \\
\hline & height & .604 & -.500 & -.052 & -.019 & 0.61 & \\
\hline \multirow{3}{*}{$\sum_{\substack{\tilde{J} \\
\Sigma}}^{\tilde{J}}$} & shape & .662 & -.431 & -.289 & .392 & 0.859 & \\
\hline & volume & 566 & -.505 & .443 & .114 & 0.783 & \\
\hline & scale & .479 & .603 & -.046 & .221 & 0.639 & \multirow{10}{*}{$\begin{array}{l}\text { The most common variable is "visual } \\
\text { compatibility" }\end{array}$} \\
\hline \multirow{6}{*}{ 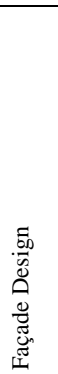 } & color & .268 & .528 & -.054 & .650 & 0.774 & \\
\hline & texture & $\begin{array}{l}.544 \\
\end{array}$ & .730 & .129 & .153 & 0.864 & \\
\hline & materials & .479 & .603 & -.046 & .221 & 0.639 & \\
\hline & style & .786 & .157 & -.434 & $\begin{array}{l}.008 \\
\end{array}$ & 0.829 & \\
\hline & openings & .842 & .034 & -.126 & -.126 & 0.739 & \\
\hline & overall details & $\begin{array}{l}.785 \\
\end{array}$ & .012 & .203 & -.208 & 0.701 & \\
\hline \multirow{3}{*}{ 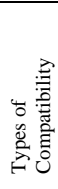 } & $\begin{array}{c}\text { visual } \\
\text { compatibility }\end{array}$ & .799 & .160 & .010 & -.107 & 1.674 & \\
\hline & $\begin{array}{c}\text { meaning } \\
\text { compatibility }\end{array}$ & .536 & .380 & -.237 & -.505 & 0.742 & \\
\hline & $\begin{array}{c}\text { historical } \\
\text { compatibility }\end{array}$ & .673 & -.338 & -.411 & -.161 & 0.759 & \\
\hline
\end{tabular}

The Laymen Component Matrix in Fatimid Cairo district shows that the façade openings, is the highest component loading among all the architectural attributes. This is because the openings are the common factor among all buildings in the street; openings have the same size, proportion and materials. Hence they can be perceived as a tool for contextual compatibility as shown in figure (27), and as indicated by the laymen in the survey. 


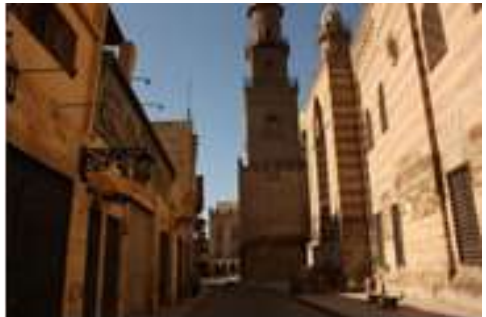

Fig. (27), Fatimid Cairo district. (Source: Authors)

While Experts' Component Matrix showing the component loading of variables in Fatimid Cairo, indicated the façade materials as the highest component loading among all variables.

While in Nasr City district, the Laymen specified the façade texture as the highest component loading among all the architectural features, they gave the high rates to two types of compatibility; the compatibility due to meaning and compatibility due to visual continuity which means that people can perceive contextual compatibility in this site, then gave a high rate also to the façade texture, the radar chart done for the component matrix in Nasr city district identifies the texture of elevations as the highest component loading and the most perceived attribute due to the laymen.

For explanatory purposes, (compatibility through visual continuity) and (compatibility through levels of meaning) were found to be the highest component loading in the previous chart, they occurred strongly in Nasr City district. This was almost equal to the results of façade features, which means that this site is compatible to some volunteers. Furthermore, the highest component loading and most perceived attribute due to experts in the same site were both the (façade style) and façade colour. Details and texture took high loadings in the same radar chart following the façade style and colour. As volunteers perceive contextual compatibility in the district through the façade style, experts found similarity between the buildings' styles along the same street, as almost all the buildings are modern and similar in the geometrical presentations as indicated in the photo questionnaire distributed to them and as shown in figure (28).

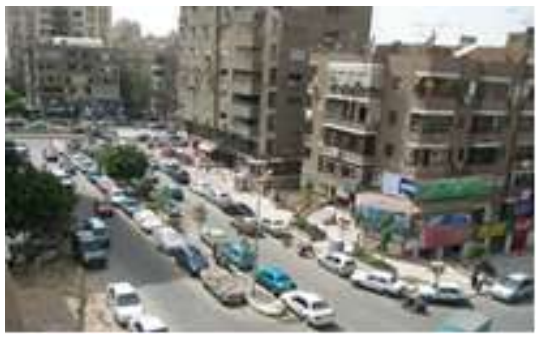

Fig. (28), Nasr City district, buildings have the same style. (Source: Authors)
While in ElKorba district, The Laymen component matrix shows that the façade style is the highest component loading among all variables. It is very surprising that the laymen had reached this result and not the experts, for the façade style is a scientific variable and most probably is perceived only by experts. However the experts' results are different, they perceive the façade colour as the most common factor in ElKorba district as the range of colour is almost the same in the whole district (see Figure (29)). In contrast, the Laymen perceive the façade style as the most common feature.

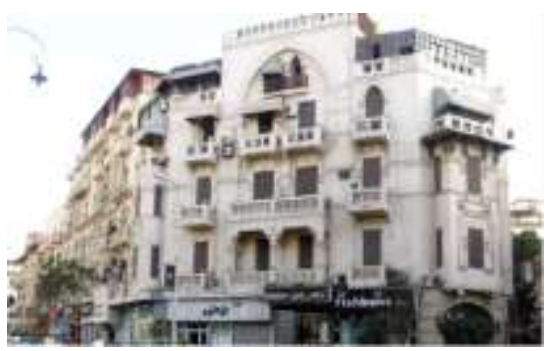

Fig. (29), El Korba district, Heliopolis, buildings have the same style and colour (Source: Authors)

Moreover the Experts Component Matrix in New Cairo district shows that the highest component loading is the façade style. New Cairo is a new residential district dedicated for the high class and 'nouveau riche' category. It shows different architectural styles but only one style within the same compound as it contains many compounds as shown in figure (30), the photo questionnaire distributed to the experts includes a photo for one of those compounds in New Cairo. The result hence indicated that the façade style is the most common factor.

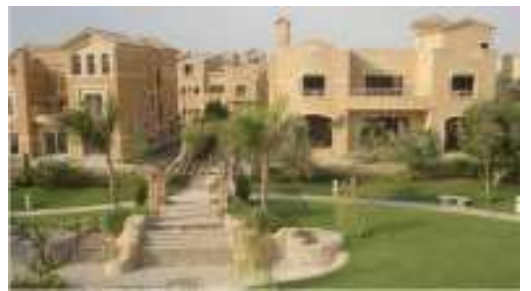

Fig. (30), one of the residential compounds in New Cairo (Source:Authors)

\section{DISCUSSION}

Discussion of contexts will be presented individually. Every context will be shown due to Laymen and due to Experts' results, showing the commonality through elements and component loading in aattempt to know which type of compatibility is shown in each context. This method of comparative analysis is indicated in figure (31) below. 


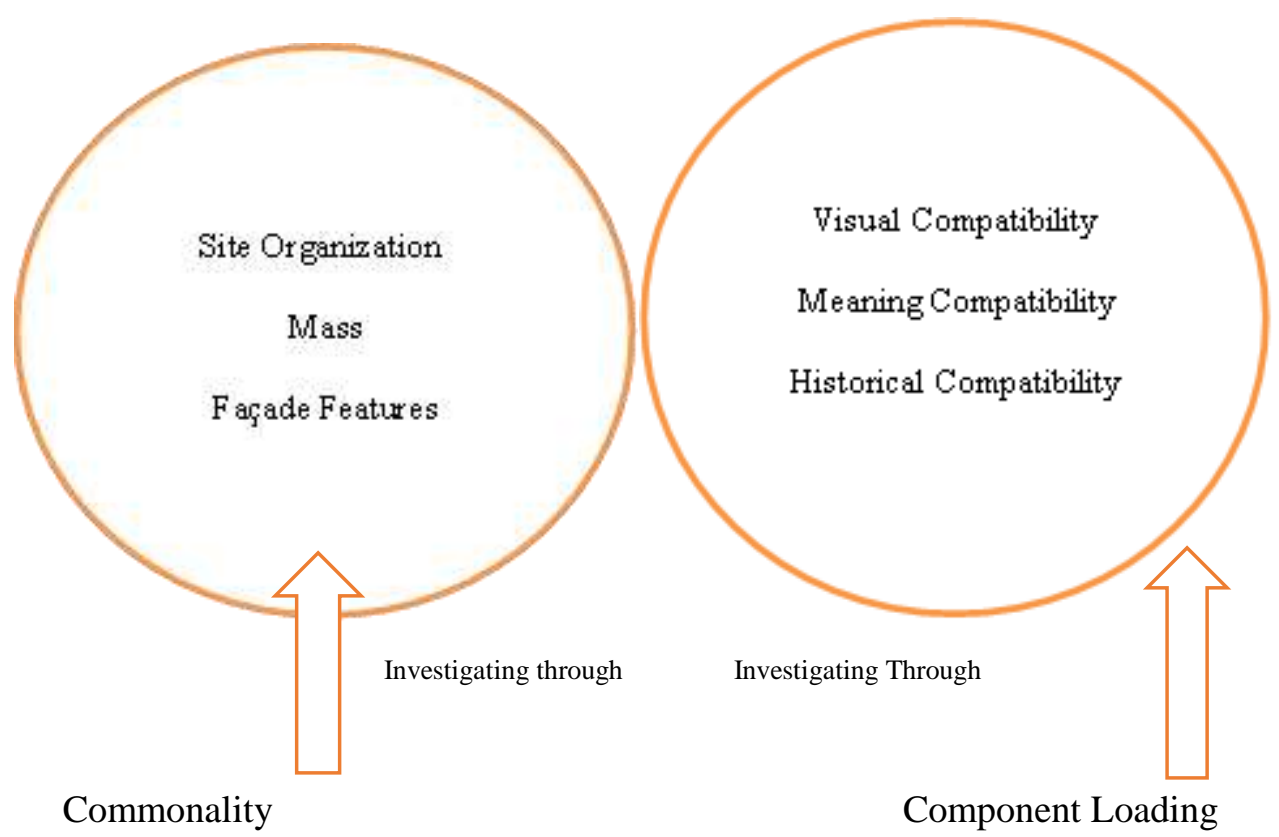

Fig. (31), a diagram explaining the strategy of discussing the results, commonality results show which of the design categories existed while component loading results show which types of compatibility existed. (Source: Authors)

\subsection{Fatimid Cairo}

$\underline{\text { Laymen }}$

Commonality indicates visual compatibility is the highest element

Component loading indicates façade openings is the highest element

\section{Experts}

Commonality indicates façade style is the highest element

Component loading indicates façade materials is the highest element

\section{Commentary}

Component loading: component matrix due to laymen shows openings as the highest loading, while due to expert shows materials as the highest loading. Façade openings in Fatimid Cairo almost have the same size, proportions, and materials. Moreover the façade openings, materials, and overall details reserve a historical image, referring to the old Fatimid era, referring also to nostalgic meanings, leading to a wellknown visual image. So Fatimid Cairo questionnaire due to Laymen and experts shows the three types of compatibility, (Visual, Meaning, Historical).

Commonality: Commonality due to laymen indicated visual compatibility is the highest element, while due to experts indicated façade style as the most common element which means (façade features) among all the three major categories.

\subsection{Nasr City}

\section{Laymen}

Commonality indicates scale is the highest element
Component loading indicates façade texture is the highest element

Experts

Commonality indicates volume is the highest element Component loading indicates façade style is the highest element

\section{Commentary}

Component loading: component matrix due to laymen shows façade texture as the highest loading, while due to expert shows façade style as the highest loading. Moreover laymen indicate meaning compatibility and visual compatibility. This is most probably because the sample photo taken in the questionnaire is for a prototype street in Nasr City including residential buildings and a ground ribbon full of colourful shops' facades. The meaning perceived by them is a geometrical and architectural meaning related to ratio, scale, openings, volumes and blocks as well. Regarding the experts questionnaire, their results approved this result as the façade style is the most component loading for them. The result for this site, it owes (visual and meaning) compatibility.

Commonality: As the research depends on commonality to discover which of the three major categories exist more in the context (mass, site organization and façade features), then by monitoring commonality in both questionnaires, it was found that commonality due to laymen indicates scale and commonality due to experts indicates volume. Both fall under (Mass) which means that masses are matching with each other in this site. 


\subsection{EI Korba}

\section{Laymen}

Commonality indicates shape is the highest element

Component loading indicates façade style is the highest element

Experts

Commonality indicates shape is the highest element Component loading indicates façade colour is the highest element

\section{Commentary}

Component loading: component matrix due to laymen shows façade style is the highest loading. Component matrix due to experts shows façade colour as the highest loading. Style and colour in El Korba facades refer to an older architectural era which holds a lot of meanings; visually and historically, thus it is shown that the three types of compatibility are visible in this context (Visual, Meaning, Historical) compatibility. Commonality: commonality results are the same for both laymen and experts, shape is the most common element determined by both laymen and experts. This means that the (Mass) is the most major element perceived by them and hence it can affect compatibility in this context.

\subsection{New Cairo}

\section{Laymen}

Commonality indicates height is the highest element Component loading indicates façade materials is the highest element

Experts

Commonality indicates height is the highest element Component loading indicates façade style is the highest element

\section{Commentary}

Component loading: component matrix due to laymen shows façade materials is the highest loading, while component matrix due to experts shows façade style as the highest loading. Hence, façade features are related mainly to visual compatibility. Since laymen perceived the materials, and experts perceived the style, they saw these two features as the most replicated and compatible items in the context. This also confirms and refers to (visual compatibility).

Commonality: commonality results are the same for both laymen and experts. Height is the most common element determined by both laymen and experts. This result is most probably because the sample photo chosen for this context was for a new residential compound in New Cairo, a prototype model with the same height, colour, materials, etc. Height falls under Site Organization. It is one of its minor elements, which means that the (Site Organization) or Site Arrangement affects the compatibility in the prototype contexts.

\subsection{EI Mohandeseen}

$\underline{\text { Laymen }}$

Commonality indicates shape is the highest element
Component loading indicates façade details is the highest element

Experts

Commonality indicates façade colour is the highest element

Component loading indicates façade colour is the highest element

\section{Commentary}

Component loading: component matrix due to laymen shows façade details is the highest loading, while the component matrix due to experts shows façade colour as the highest loading, façade features are related mainly to visual compatibility. Since laymen perceived the details, and experts perceived the colour, they saw these two features as the most replicated and compatible in the context, which refers to (visual compatibility). They can see the context compatible only visually.

Commonality: commonality results are not the same for both laymen and experts, laymen indicates shape as the most common element in the context, and this fall under (Mass), while experts indicates façade colour as the most common element in the context, and this fall under (Façade features).

\section{CONCLUDING REMARKS}

In general, the previous analysis show that many volunteers realized compatibility due to visual continuity in almost all the sites, especially in Mohandeseen, Nasr City and Fatimid Cairo. The other two types of compatibility (compatibility through levels of meaning, and compatibility as a reflection of history) gained fewer grades in the questionnaire just as shown in the previous discussion. Moreover the façade features had gained the highest component loading among all contextual variables. There reason that possibly lay behind these results is that the façade features are easily observed and appear adequately clear through the whole composition of the context.

\section{FINDINGS}

The findings of this research highlighted three conclusions: first the façade features: colour, texture, materials, style, openings, overall details have the big loading in all variables, which verified the research hypothesis that the façade components have the strongest effect on compatibility judgment. Second there is quite a difference between preferences done by laymen and appropriateness stated by experts. Architects are still aware of site organization and masses in the context, although the main issue for contextual compatibility due to them is the façade components and details. Third, is that compatibility due to visual continuity is the most perceived due to results from both laymen and experts which also verifies the statedhypothesis. Moreover the only two contexts that hold the three types of compatibility were (Fatimid Cairo and El Korba) which means applying compatibility interpretations depends on history, 
traditions, meanings and different concepts not only physical components. Architects and Urban designers should take into consideration the layman's perspective which depends on deeper and rooted beliefs, behaviours, observations, etc., and which is by proof and evidence different than the expert's eye. A thorough investigation in this regard should be undertaken prior to developing designs especially in historic or valuable urban contexts.

\section{REFERENCES}

[1] Abu-Obeid, N., Malkawi, F. K., Nassar, K., Al-eideh, B.,2009, "Cognitive-Mathematical Approaches for Evaluating Architectural Contextual Fit”, pp. 164167.

[2] Groat, L., 1983, "Measuring the Fit of New to Old", in D.,Canter, M.,krumpn, D., Ska (eds), "Environmental Perspectives", Aldershot, Avebery, pp. 58-61.

[3] Lefebvre, H., 1996, "Writings on Cities", Wiley Press, pp.104-108.

[4] Lefebvre, H., 2003, “The Urban Revolution”, University of Minnesota Press, pp.100-110.

[5] Lefebvre, H., 2009, "State, Space, World", selected essays, University of Minnesota Press, pp.60-66.

[6] Brolin, B. C., 2002, "Architecture in context: Fitting new buildings with old", Van Nostrand Reinhold, New York, p.35.

[7] Groat, L., 1995, "Giving Places Meaning”, in Canter, D., "Readings in Environmental Psychology" College of Architecture and Urban Planning, University of Michigan, USA, p.29, p.115,p. 185.

[8] Rapoport, A., 1982, "The Meaning of the Built Environment", Sage Publications, USA, p.16

[9] Auburn, T. and Barnes, R., 2006, "Producing place: A neoSchutzian perspective on the psychology of place", Journal of Environmental Psychology, volume 26, www.elsevier.com, pp 40-43.

[10] Kjellström, H., 2011, "Contextual Action Recognition", Stockholm, Sweden, p.361.

[11[ Nasar, J. L., 1989, "Perception, Cognition, and Evaluation of Urban Places", in Altman, I. and Zube, E. H., "Public Places and Spaces", New York, pp. 34-37.

[12] Lynch, K., 1960, "The Image of the City", Harvard College, United States of America, pp.50-80.
[13] Alexander, C., Ishikawa, S., \& Silverstein, M., 1977, “A Pattern Language: Towns, buildings, construction", New York, NY: Oxford University, p.10.

[14] Jencks, C., and Kropf, K., 1999, "Theories and Manifestoes of Contemporary Architecture", Academy Editions, Great Britain, p. 19.

[15] Cullen, G., 1991, "Townscape", Springer, pp.100-110.

[17] Cullen, G., 2012, "The Concise Townscape", Routledge, p.77.

[18] Altman, I. and Chemers, M., 1980, "Culture and Environment", Boston, Cambridge University Press, p.60.

[19] Banerjee, T. and Southworth, M., 1990, "City Sense and City Design: Writings and Projects of Kevin Lynch", MIT Press.

[20] Groat, L., 1988, "Contextual Compatibility in Architecture", 1988, in D.,Canter, M.,Krumpn, D., Ska (eds.), "Environmental Perspectives", Aldershot, Avebery, p.224.

[21] Groat, L., 1988, "Contextual Compatibility in Architecture: an issue of personal taste?" in D.,Canter, M., krumpn, D., Ska (eds.), "Environmental Perspectives", Aldershot, Avebery, p. 230 .

[22] Vahabzadeh, P., 2001, "A Critique of Ultimate Referentiality in the New Social Movement Theory of Alberto Melucci", The Canadian Journal of Sociology, Vol. 26, http://www.jstor.org/stable/3341494, p.611.

[24] Davis, H., 1999, "The Culture of Building", New York, NY, Oxford University Press, p.3.

[25] Lessig, L., 1998, "The Architecture of Privacy", Taiwan Net'98 conference, Taipei, p.2.

[26] Rice, G. E., 1980, "On cultural Schemata”, Arizona State University, American Ethnologist, Vol. 7, No. 1, Wiley, in http://www.jstor.org/stable/643431, p.152154.

[27] Milligan, J. R., 1979, "Schema Learning Theory: An Approach to Perceptual Learning", review of educational research, vol. 49, American Educational Research Association, http://www.jstor.org/stable/1169958, p.197.

[28] Plata, M., 2009, "Cultural Schemata-Yardstick for Measuring Others: Implications for Teachers", Journal of Instructional Psychology, vol. 38, no. 2, p.117.

[29] Hennink, M., Hutter, I., Bailey, A., 2011, "Qualitative Research Methods", Sage Publications, p.10, 1 